\title{
Avulsion of the flexor digitorum tendon secondary to enchondroma of the distal phalanx
}

\author{
Winnie Wong MD, Karen Cross MD, James Mahoney MD FRCSC
}

\begin{abstract}
W Wong, K Cross, J Mahoney. Avulsion of the flexor digitorum tendon secondary to enchondroma of the distal phalanx. Can J Plast Surg 2004;12(2):67-68.

Flexor digitorum profundus (FDP) tendon avulsion is a common injury in sports. This is secondary to forced extension against flexor digitorum profundus contraction. However, avulsion injury of the FDP tendon secondary to an enchondroma of the distal phalanx is extremely rare. There have only been three previous reports of such an occurrence. This report describes a fourth case of an avulsion injury of the FDP tendon secondary to enchondroma of the distal phalanx of the fourth digit.
\end{abstract}

Key Words: Distal phalanx; Enchondroma; FDP avulsion fracture

\section{L'avulsion du tendon fléchisseur des doigts secondaire à un chondrome de la phalange distale}

L'avulsion du tendon fléchisseur profond (TFP) est une blessure sportive courante, secondaire à une extension forcée à la contraction du TFP. Cependant, une lésion d'avulsion du TFP secondaire à un chondrome de la phalange distale est d'une extrême rareté. Seulement trois cas de ce genre ont été déclarés. Le présent compte rendu décrit un quatrième cas de lésion d'avulsion du TFP secondaire à un chondrome de la phalange distale de l'annulaire.

\begin{abstract}
A 38-year-old right-hand-dominant man, otherwise healthy, experienced severe pain in his left fourth digit after he accidentally tapped his hand on a cleat while sailing. On clinical examination, the left fourth distal interphalangeal (DIP) joint was tender and swollen with loss of active flexion. A review of the $\mathrm{x}$-rays showed an avulsion fracture and a welldefined geographic lytic lesion, consistent with an enchondroma, at the base of the distal phalanx (Figure 1).

One week after the initial injury, surgical exploration was initiated with an incision over the palmar aspect of the DIP joint. The fracture site was identified at the distal phalanx. The profundus tendon was attached to the avulsed fragment, which had retracted to the A4 pulley. The enchondroma was exposed and removed by curettage creating a corticocancellous bone defect. A bolster suture was used to fix the avulsed fragment to the distal phalanx (1). Pathology was sent and confirmed the diagnosis. Postoperatively, the fourth and fifth digits were kept in flexion with a dorsal splint. Physiotherapy and active exercises began at three weeks. After a four-month course of physiotherapy the patient was pain free, with $52^{\circ}$
\end{abstract}

active flexion and $-10^{\circ}$ active extension of his left fourth DIP. A review of $x$-rays taken five months postoperatively shows the previously avulsed articular fragment to be reduced and healed in place (Figure 2). The patient remained pain free seven months postoperatively.

\section{DISCUSSION}

Enchondroma, a benign tumour arising from the medullary cavity of bone, is the most common benign tumour of the hand. It occurs primarily in the second and third decades of life, with the proximal phalanx being the most common location. Enchondroma in the distal phalanx is rare and only a small number of cases have been reported in the literature (2-4).

Typically, an enchondroma presents with pain, swelling and/or a pathological fracture, though many are found incidentally on $\mathrm{x}$-ray in asymptomatic patients. A pathological fracture often occurs after a relatively trivial injury. The usual approach is to let the fracture heal and subsequently treat the enchondroma. Shimizu et al (5) reported several cases of pathological fracture that presented with pain and 


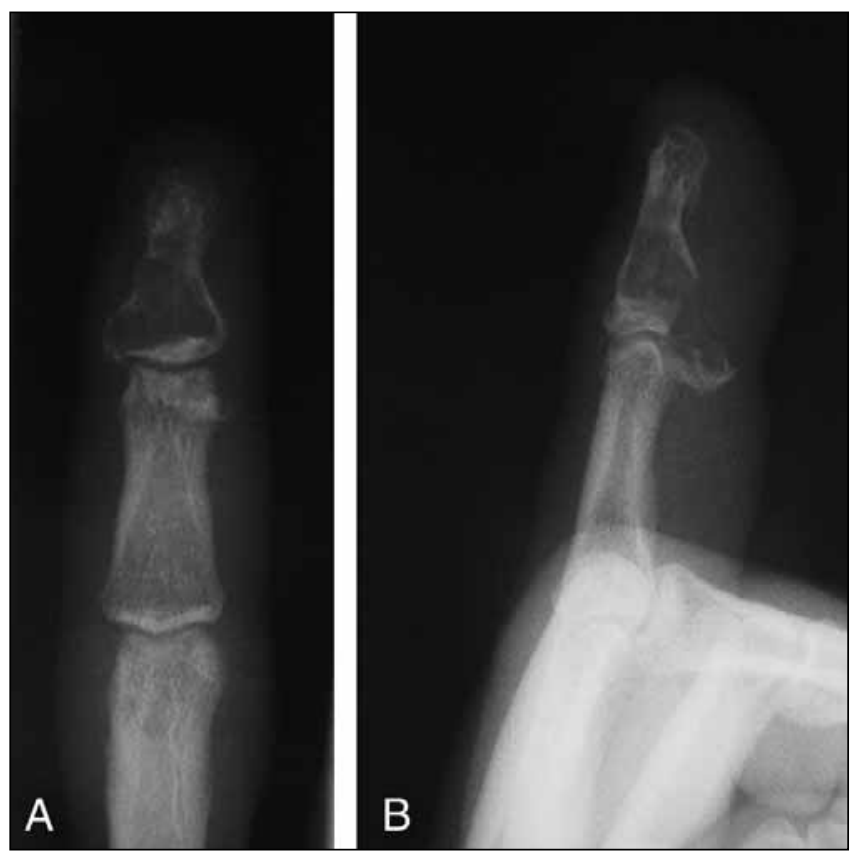

Figure 1) Enchondroma of the left, fourth distal phalanx. A Posteroanterior view. B Lateral view, fracture of the base of the distal phalanx with avulsed bony fragment

roentgenographic findings, but no avulsion of the FDP tendon was reported. Only three previous reports have described an avulsion of the FDP tendon secondary to an enchondroma of the distal phalanx (2-4). Similar to these three cases, our patient was asymptomatic before the injury.

There is a consensus in the literature that a definitive diagnosis of an enchondroma can not be made based on roentgenogram findings alone. Although uncommon in the phalanges, a low grade (grade 1) chondrosarcoma shares many of the radiological features of benign enchondromas (6). Hence, differentiation between these two lesions requires histological assessment of a surgical specimen.

This case differs from the three previously reported cases because a bone graft was not used to fill the defect left by curettage. This is a well accepted method of repair because patients treated with curettage alone will form new bone to fill in the surgical cavity $(7,8)$. It has been hypothesized that the hematoma at the fracture site becomes invaded by mesenchymal multipotent cells which can differentiate into osteoblasts providing the cellular network for bone growth (8). Using curettage alone may decrease the risk of infection, bleeding

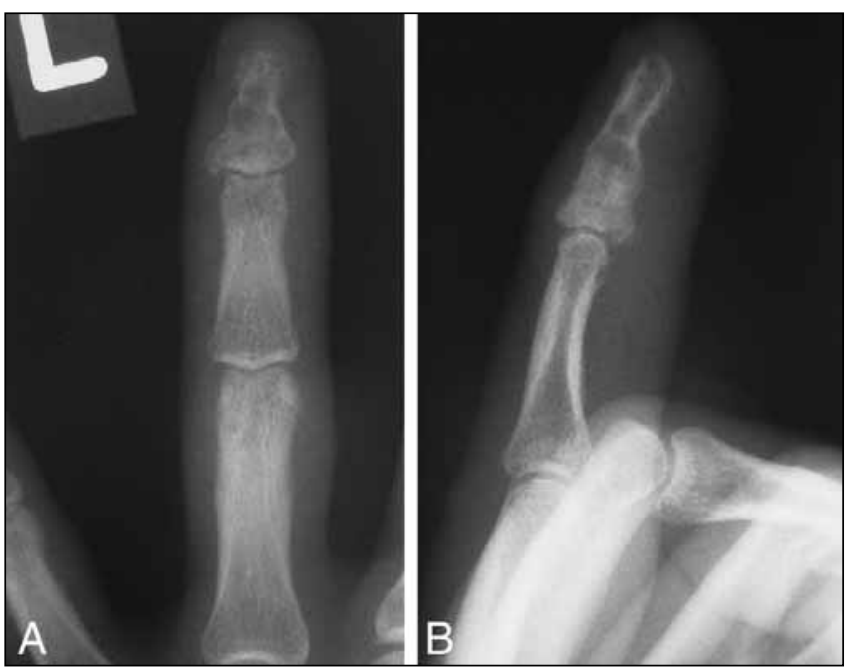

Figure 2) Left fourth distal phalanx five months postoperatively. A Posteroanterior view. B Lateral view, previously avulsed articular fragment is reduced and healed in place

and rejection of bone graft. With no donor site patients can be mobilized earlier resulting in a shorter duration away from work which aids rehabilitation.

This case describes a rare presentation of enchondroma. As with other flexor tendon avulsion injuries early exploration is recommended. A satisfactory outcome can be achieved by using a pull-out tendon advancement technique.

\section{REFERENCES}

1. Ogunro O. Avulsion of flexor profundus, secondary to enchondroma of the distal phalanx. J Hand Surg 1983;8:3:315-6.

2. Froimson AI, Shall L. Flexor digitorum avulsion through enchondroma. J Hand Surg [Br] 1984;9:3:343-4.

3. Canovas F, Nicolau F, Bonnel F. Avulsion of the flexor digitorum profundus tendon associated with a chondroma of the distal phalanx. J Hand Surg [Br] 1998;23:130-1.

4. Kleinert HE, Smith DJ. Primary and secondary repairs of flexor and extensor tendon injuries. In: Jupiter JB, ed. Flynn's Hand Surgery, 4th edn. Baltimore: Williams \& Wilkins, 1991:243-5.

5. Shimizu K, Kotoura Y, Nishijima N, Nakamura T. Enchondroma of the distal phalanx of the hand. J Bone Joint Surg 1997;79:898-900.

6. Wang XL, De Beuckeleer LH, De Schepper AMA, Van Marck E. Low-grade chondrosarcoma vs enchondroma: Challenges in diagnosis and management. Eur Radiol 2001;11:1054-7.

7. Hasselgren G, Forssblad P, Tornvall A. Bone grafting unnecessary in the treatment of enchondromas in the hand. J Hand Surg [Am] 1991;16:139-42.

8. Tordai P, Hoglund M, Lugnegard $\mathrm{H}$. Is the treatment of enchondroma in the hand by simple curettage a rewarding method? J Hand Surg [Br] 1990;15:331-4. 